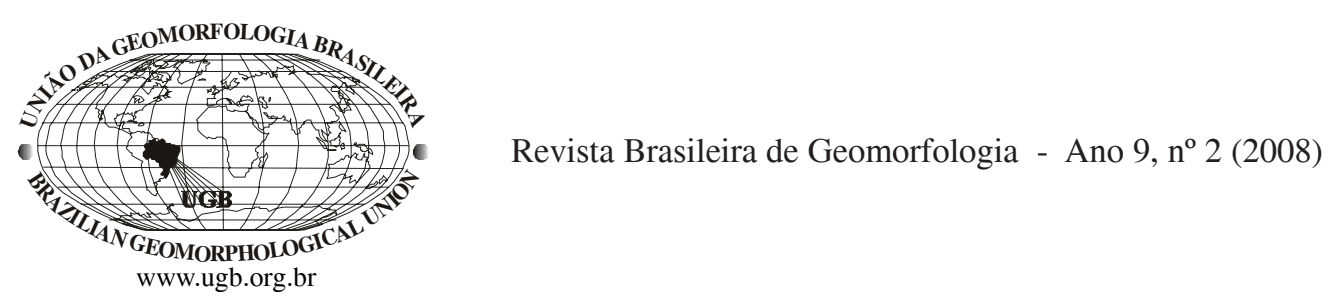

\title{
SUAVIZAÇÃO DOS CONTATOS ENTRE COMPARTIMENTOS DE RELEVO ATRAVÉS DE MODELAGEM POR INFERÊNCIA FUZZY: MAPEAMENTO GEOMORFOLÓGICO NO MUNICÍPIO DE PRESIDENTE PRUDENTE - SP - BRASIL
}

\author{
Tiago Matsuo Samizava \\ Mestrando em Ciências Cartográficas - Universidade Estadual Paulista (UNESP) \\ tiagosamizava@yahoo.com.br
}

João Osvaldo Rodrigues Nunes

Professor Doutor - Universidade Estadual Paulista (UNESP)

joaosvaldo@fct.unesp.br

Nilton Nobuhiro Imai

Professor Doutor - Universidade Estadual Paulista (UNESP) nnimai@fct.unesp.br

Rodrigo Hiroshi Kaida

Engenheiro Ambiental - Universidade Estadual Paulista (UNESP)

rodrigohk@gmail.com

\begin{abstract}
Resumo
Os compartimentos de relevo presentes em mapas geomorfológicos são delimitados por polígonos fechados. Nesse processo de mapeamento, a incerteza presente na delimitação dos polígonos é grande, já que as classes não são homogêneas. Esse tipo de representação espacial conduz a dados imprecisos em mapas com limites rígidos e introduz erros desnecessários em estágio inicial do processo de utilização dessa informação numa inferência espacial. Nesse contexto, o presente artigo utiliza uma metodologia baseada em inferência fuzzy, para modelagem de uma representação computacional de compartimentos de relevo, considerando a natureza imprecisa dos contatos entre as classes temáticas. A área de estudo localiza-se no município de Presidente Prudente - SP.
\end{abstract}

Palavras-chave: mapeamento, geomorfologia, modelagem, lógica fuzzy, Presidente Prudente.

\begin{abstract}
Relief compartments of the geomorphological maps are represented by polygons closed. The uncertainty of the process of drawing polygons is caused by the heterogeneity of classes. This imprecise representation of spatial data with sharp limits introduces unnecessary errors on process of spatial inference. In this context, this paper adopts a methodology based on fuzzy inference for modeling compartments of relief as a more consistent computer representation, given the imprecise feature of the contacts between thematic classes. The area of study is located in the Presidente Prudente-SP County.
\end{abstract}

Keywords: mapping, geomorphology, model, fuzzy logic, Presidente Prudente. 


\section{Introdução}

Com o desenvolvimento de ferramentas disponíveis em softwares de geoprocessamento, os mapas geomorfológicos, geralmente espacializados bidimensionalmente, são transformados, principalmente para sua integração com outros modelos da superfície do terreno. A Geomorfologia que, por excelência, trabalha com a tridimensionalidade, adota como uma de suas metodologias a extração de informações sobre os compartimentos e feições de relevo, geralmente a partir de técnicas de interpretação de fotos aéreas ou de imagens de satélites.

Para a elaboração de mapas geomorfológicos, conforme o objetivo a ser alcançado, o pesquisador deve ter a preocupação de apresentar e demonstrar o mais didático possível, as características de identificação, classificação (gênese e idade) e os processos morfodinâmicos e morfogenéticos do relevo. Além destes aspectos, destaca-se entre outros, a geologia (Formações litológicas) e a pedologia (classes de solos). Também é de fundamental importância a escala de abordagem a ser utilizada, pois de acordo com a escala de representação cartográfica, o documento apresentará um grau maior ou menor de detalhamento (NUNES, FREIRE e PEREZ, 2006).

Os mapas geomorfológicos têm mostrado grande importância nos estudos ambientais, principalmente como entrada nos modelos desenvolvidos em Sistemas de Informação Geográfica (SIG) (NUNES et al., 2006; SAMIZAVA et al., 2008).

Normalmente, intérpretes utilizam feições observáveis, tais como: mudança de cores, padrão de textura e quebra de encosta, para inferir contatos no processo de elaboração de mapas geomorfológicos. Cartograficamente esses contatos são definidos por linhas ou polígonos, que podem representar uma limitação na representação espacial dos elementos do terreno necessárias em uma modelagem desenvolvida em ambiente SIG (BURROUGH, 1996; MOREIRA, 2001; SILVA e PEJON, 2004).

Dessa forma, as feições geomorfológicas extraídas e delimitadas por linhas ou polígonos apresentam incerteza e imprecisão. Por exemplo, variações morfológicas do relevo podem expressar mudanças litológicas que ocorrem em centenas de metros ou quilômetros, que é inerente à escala de representação geomorfológica. Com exceção de áreas escarpadas, as quais possuem zonas de transição abruptas devido a mudanças repentinas na declividade do terreno, os limites na natureza não são rígidos, possuindo variação contínua no espaço.

Para Goodchild et al. (1993), a fonte de incerteza no polígono é derivada pelo processo de digitalização. Entretanto, os erros introduzidos pela digitalização são muito pequenos quando comparado com a incerteza presente na zona de transição entre os polígonos, já que as regiões/áreas de uma classe não são homogêneas (ALTMAN, 1994).

Burrough e Heuvelink (1992) demonstram que os modelos baseados em lógica booleana estão muito mais sujeitos à propagação de erros em modelagens, enquanto que a lógica fuzzy mostrou-se mais adequada por permitir aos usuários que definam classes de funções de pertinência baseado em experiências práticas e dessa forma pode reduzir drasticamente a propagação de erros.

Nesse contexto, a utilização da lógica fuzzy na representação dos contatos entre regiões/áreas de diferentes classes possibilita a incorporação da informação sobre a natureza dos contatos geomorfológicos, bem como da incerteza associada à classificação e ao posicionamento. Burrough e McDonell (1998) propõem uma técnica para a representação da informação semântica de contatos fuzzy, denominada "abordagem por unidades de mapa" (map unit approach). A necessidade de aprimoramento da representação da forma tradicional de feições geomorfológicas decorre da sua integração com outras informações da superfície do terreno para produção de sínteses que expressem a realidade geográfica. Nesses casos, esses aprimoramentos podem conduzir resultados mais apropriados, os quais possuam maior aderência com a realidade geográfica e ofereçam maior segurança na sua utilização em tomadas de decisão.

Assim, o presente artigo apresenta uma metodologia, baseada em importação semântica de contatos fuzzy, para modelagem e representação computacional da natureza imprecisa dos contatos ou limites entre compartimentos de relevo do mapa geomorfológico. Esse tipo de abordagem, com suas adaptações, vêm sendo utilizado nas mais diversas aplicações, como em trabalhos de Lagacherie et al. (1996), Moreira (2001), Pejon e Silva (2004).

No presente caso, será aplicada a modelagem por inferência fuzzy para um mapa de compartimentos geomorfológicos no município de Presidente Prudente-SP, que abrange o perímetro urbano da cidade (Figura 1). A área geográfica em estudo é definida por coordenadas planas, referenciadas ao sistema de projeção UTM (Universal Transversa de Mercator), zona 22, sistema de referência córrego Alegre, delimitada por coordenadas E entre 450.860,0 e 465.020,0, e $\mathrm{N}$ entre 7.545.740,0 e 7.559.200,0.

\section{Procedimentos Metodológicos}

Os compartimentos geomorfológicos foram obtidos a partir do Mapa Geomorfológico do perímetro urbano de Presidente Prudente, elaborado por Nunes, Freire e Perez (2006), através de interpretação de fotos aéreas de 1995, na escala de 1:25.000, com estereoscópio de espelho. Nesse mapa, a extração das feições geomorfológicas foi realizada com base nas chaves de interpretação como textura, estrutura, forma, 
padrão e tonalidade. A atualização do mapa foi realizada com trabalhos de campo e ortofotos digitais na escala de 1:8000, de 2003. Para a correção ortogonal das feições foi utilizada uma base planoaltimétrica digital, na escala de 1:10.000.

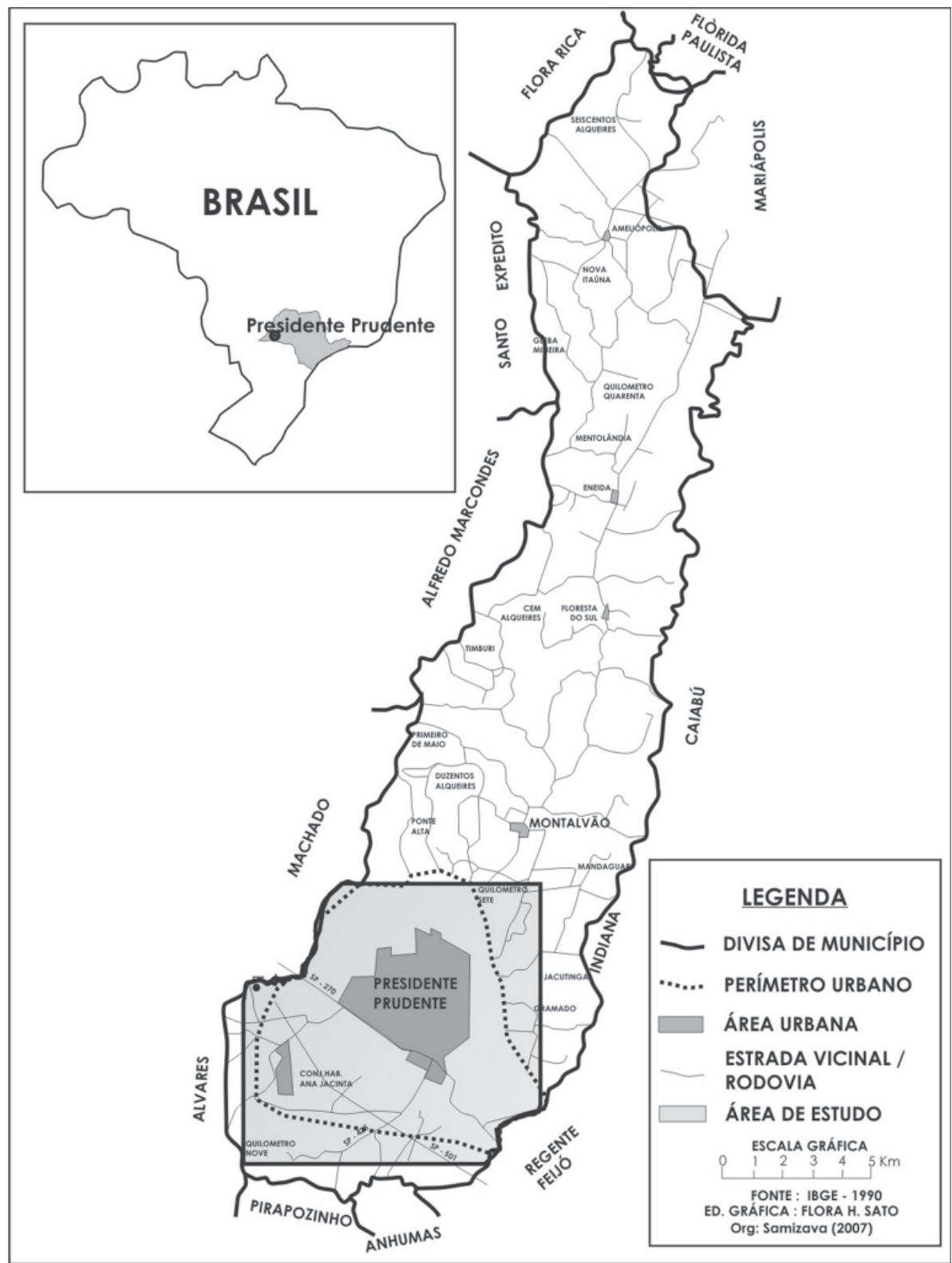

Figura 1 - Localização da área de estudo no município de Presidente Prudente.

Para o processo de suavização dos contatos, primeiramente foi realizada uma avaliação da distância da zona de transição a ser adotada para os limites das classes vertentes-topos e planícies-vertentes. Definida a zona de transição, analisouse a morfologia do relevo, extraindo uma amostra de perfis topográficos em zonas de transição, para as quais foram ajustadas funções polinomiais pelo método dos mínimos quadrados. A modelagem por uma função polinomial buscou mode- lar a tendência presente no perfil de variação da altimetria do terreno, para assim definir uma função fuzzy que represente a zona de transição. Essas análises foram realizadas com base em representações computacionais do relevo do tipo grade numérica, ou seja, em representações matriciais tanto da altimetria como da declividade, obtidas de dados amostrais das curvas de nível da base planoaltimétrica digital do município de Presidente Prudente. 
Definidos a zona de transição e o tipo de função fuzzy, a aplicação da modelagem dos contatos entre polígonos dos compartimentos geomorfológicos foi realizada no software SPRING 4.3.3@, no qual foi implementado um código em linguagem de programação. O algoritmo é baseado na abordagem de importação semântica por unidades de mapa, proposto por Burrough e MacDonell (1998). Essa abordagem possibilita uma representação única para os contatos das unidades ou polígonos. Ou seja, essa técnica assume que o limite da classe apresenta um único tipo de contato ao longo do seu perímetro. As informações sobre o tipo de contato podem ser convertidas nos parâmetros necessários para a definição da função membro fuzzy, as quais são aplicadas sobre o plano de informação que contém a grade de distância isotropicamente distribuída ao longo dos contatos do polígono.

Outros procedimentos de processamento de imagens foram realizados no software IDRISI ANDESC .

Foi adotado o erro absoluto gráfico de $0,2 \mathrm{~mm}$ de uma feição na representação cartográfica, resultando numa resolução espacial de $5 \mathrm{~m}$, devido à escala do mapa geomorfológico (1:25.000). Esse erro está associado na capacidade visual do ser humano em não distinguir segmentos que distam mais que $0,2 \mathrm{~mm}$.

\section{Resultados e discussões}

A seguir serão apresentados os resultados da aplicação da metodologia adotada nesse trabalho.

\section{Os compartimentos geomorfológicos}

Segundo Nunes (2002) e Nunes, Freire e Perez (2006), os compartimentos geomorfológicos mapeados no município de Presidente Prudente foram identificados como (Figura 2):

- Topo suavemente ondulado das colinas convexizadas (altitude média de 430 a 480 metros metros), com predomínio de solos do tipo Latossolos, profundos e bem desenvolvidos, com declives suaves (2 a $8 \%$ );

- Domínio das vertentes côncavo-convexas (altitude média entre 420 a 450 metros) com predomínio de solos Argissolos e Neossolos, mormente rasos e com declividades mais acentuadas (8 a maiores que 20\%);

- Planície Aluvial e Alvéolos (altitude média de 380 a 420 metros), com predomínio de Gleissolos e Planossolos, identificados em declives baixos (0 a 2\%).

\section{Definição da zona de transição}

A definição da zona de transição foi estabelecida com base no conhecimento do especialista, que no momento de interpretação visual das fotos aéreas, pôde definir uma zona de imprecisão inerente ao limite dos compartimentos, ao processo de extração de feições e à limitação decorrente da resolução espacial ou escala das fotos interpretadas. Dessa forma foi definida uma distância de $50 \mathrm{~m}$ para a zona de transição entre a planície e vertente, e de 100 m entre os topos e vertentes.

A fim de verificar a coerência dos limites definidos foi realizada uma análise exploratória sobre uma superfície de declividades obtida através de um conjunto de dados altimétricos do mapa do Município de Presidente Prudente na escala 1:10.000, em Projeção UTM - córrego Alegre, já que essa variável permite ser utilizada num critério objetivo de análise das formas de relevo, uma vez que ela indica o grau de inclinação do terreno em cada posição. Essa superfície de declividade foi gerada a partir de uma triangulação Delanay sobre curvas de nível com eqüidistância de $10 \mathrm{~m}$.

A zona de transição entre os compartimentos topo e vertentes foram fatiadas em classes com intervalos de distância de $5 \mathrm{~m}$. Essas classes foram cruzadas com dados de declividade a fim de obter os valores médios da declividade para cada classe fatiada na zona de transição. Verificou-se para a zona de transição entre topos e vertentes, como era esperado, que a declividade aumenta no sentido topo-vertente. A variação no inicio da zona de transição no topo tem declividade média de $6,2 \%$; enquanto que no limite da zona de transição na vertente o valor de declive médio é de $10,6 \%$.

Esse procedimento foi realizado, da mesma forma, para a zona de transição entre a planície aluvial e as vertentes. Nota-se que no limite da planície a declividade média é de $7,4 \%$ e no limite da zona de transição na vertente a declividade média é de $10,7 \%$. Esse fato mostra que houve coerência na definição da zona de transição entre as classes geomorfológicas.

\section{Análise da forma do relevo e definição das funções de pertinência $f u z z y$}

Buscando analisar a morfologia do relevo, foram extraídos alguns perfis topográficos na zona de transição vertente-topo e ajustado funções polinomiais pelo método dos mínimos quadrados (Figura 3). Dentre os perfis, foram escolhidos dois, pois se tratam de áreas em que existe um conhecimento prévio adquirido em estudos anteriores e que representam os tipos de relevo que podem ser encontrados no município. O perfil A localiza-se no conjunto habitacional Ana Jacinta, a qual apresenta pequenas rupturas de declive; o perfil B trata-se do local estudado para instalação de um aterro sanitário no bairro do Limoeiro. Ambos os perfis localizam-se na porção sudoeste do município. 

município de Presidente Prudente - SP - Brasil

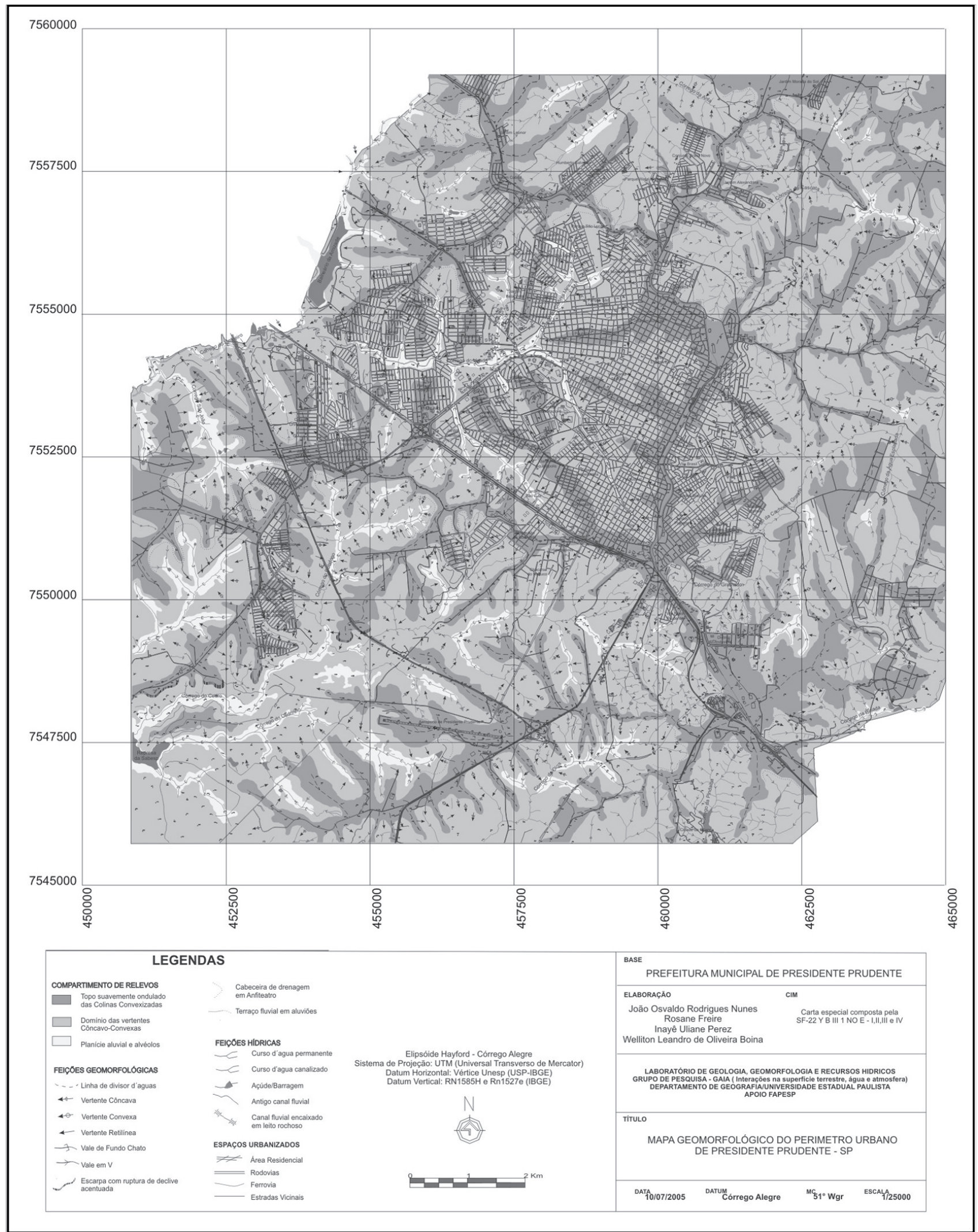

Figura 2 - Mapa geomorfológico de Presidente Prudente-SP onde foi aplicada a metodologia de suavização entre os limites dos compartimentos de relevo. 

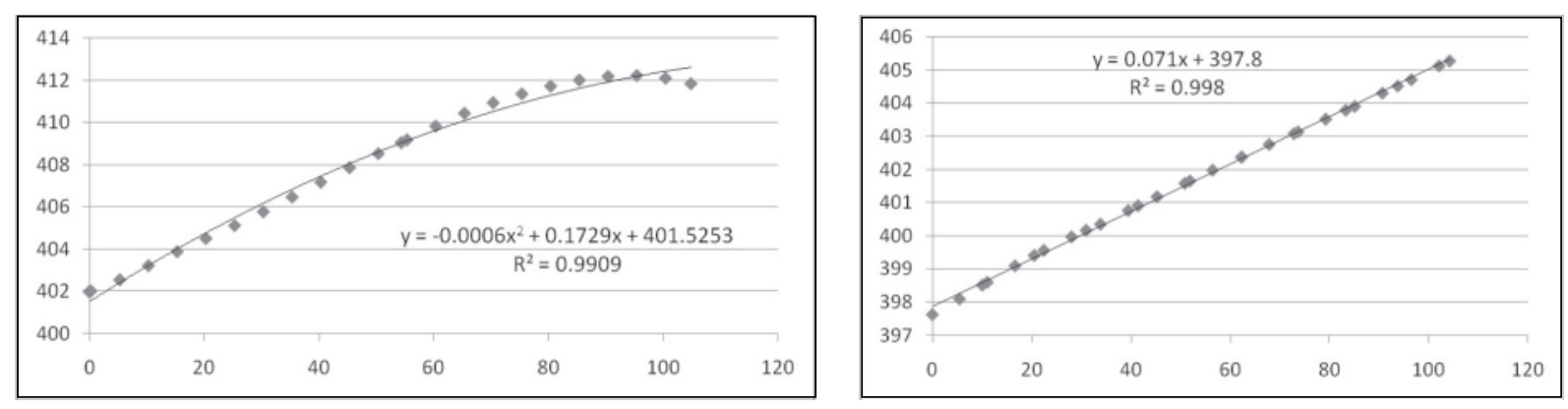

Figura 3 - Perfil A, ajuste com uma função de segundo grau com $R^{2}$ de 99,09\%. Perfil B, ajuste com uma função linear com $R^{2}$ de $99,8 \%$. A posição 0 trata-se do limite da zona de transição na vertente e a distância 100 representa o limite da zona de transição nos topos.

O ajuste de uma função polinomial sobre a topografia do terreno tenta modelar uma tendência espacial associada à zona de transição. Fica evidente que essa tendência existe e que é possível modelá-la com alta representatividade da variância (coeficiente de determinação maior que $99 \%$ ).

Nota-se que, a derivada da função ajustada é a inclinação angular da curva que representa o perfil do terreno, ou seja, a inclinação do terreno em cada posição. Dessa forma, a derivada do perfil A resulta numa função linear. Ou seja, de acordo com essa representação analítica, a declividade da região de transição varia linearmente no espaço. Para o perfil $\mathrm{B}$, a declividade é constante para cada posição no espaço ao longo da região de transição entre as áreas de diferentes classes geomorfológicas.

Dessa forma, adotando-se a declividade como critério objetivo para modelagem do grau de pertinência para cada compartimento de relevo, uma função fuzzy linear é mais apropriada para descrever a taxa de variação da declividade para cada posição da zona de transição. Essa conclusão baseia-se nos resultados obtidos de declividade média no início e no final de regiões consideradas como sendo de transição entre áreas de diferentes classes.

Esse mesmo procedimento foi efetuado para a zona de transição entre a planície-vertente, na qual a função de segundo grau melhor ajustou-se ao conjunto amostral. Da mesma forma que a transição entre topo e vertente e sua derivada é uma função linear.

Entretanto, partindo do conhecimento empírico do especialista, o grau de pertinência em relação à incerteza dos limites dos compartimentos de relevo não tem variação linear no espaço. $\mathrm{O}$ ensaio realizado, ajusta funções buscando modelar a taxa de variação da declividade no terreno, que corresponde ao processo de mapeamento, nem sempre associado ao grau de pertinência inerente às formas de relevo. As características de um compartimento são mais próximas entre si nos limites das zonas de transição e quanto mais distan- tes a incerteza associada torna-se mais acentuada. Para a modelagem desse tipo de aplicação, uma função sigmoidal apresenta-se mais adequada.

\section{Aplicação de lógica fuzzy para modelagem das zonas de transição dos compartimentos geomorfológicos}

A representação computacional dos compartimentos geomorfológicos na estrutura de dados do tipo grade numérica mais adequada para sua integração com outras variáveis em processos de inferência geográfica - resulta numa superfície numérica que varia de 0 a 1 , de acordo com o grau de pertinência de cada elemento da grade para cada compartimento temático. A geração de representação numérica (MNT) dos compartimentos de relevo com suavização dos limites entre áreas de diferentes classes temáticas foi realizada a partir da combinação de funções de ponderação para as classes temáticas e de funções pertinência fuzzy para modelar intervalos de incerteza inerente aos compartimentos geomorfológicos.

Para cada classe temática foram atribuídos valores por meio de ponderação e os contatos entre classes foram modelados a partir de funções lineares e sigmoidais, segundo o critério objetivo da declividade e do especialista, respectivamente.

As operações foram realizadas em linguagem de programação, no módulo LEGAL - Linguagem Espacial para Geoprocessamento Algébrico, do SPRING. Para tanto, primeiramente foram produzidos mapas de distâncias "dist_topos" e "dist_planicie", que se referem a um mapa de distâncias gerado a partir dos polígonos ou linhas (limites) entre regiões de classes de topos e vertentes e entre as áreas das classes de vertente e planície, respectivamente. O cálculo das distâncias foi realizado por uma rotina que computa, em cada célula, a distância mínima entre essa célula e a feição de interesse, no caso os contatos dos polígonos que re- 
Suavização dos contatos entre compartimentos de relevo através de modelagem por inferência Fuzzy: mapeamento geomorfológico no município de Presidente Prudente - SP - Brasil

presentam as classes temáticas. Também é conhecido como mapa de distância isotrópico.

Assim, o código gerado utilizou operadores condicionais, expressões booleanas e matemáticas, apresentado na
Figura 4. Esse processamento já produz uma representação num intervalo de valores previamente selecionado para indicar a pertinência em relação aos compartimentos geomorfológicos.

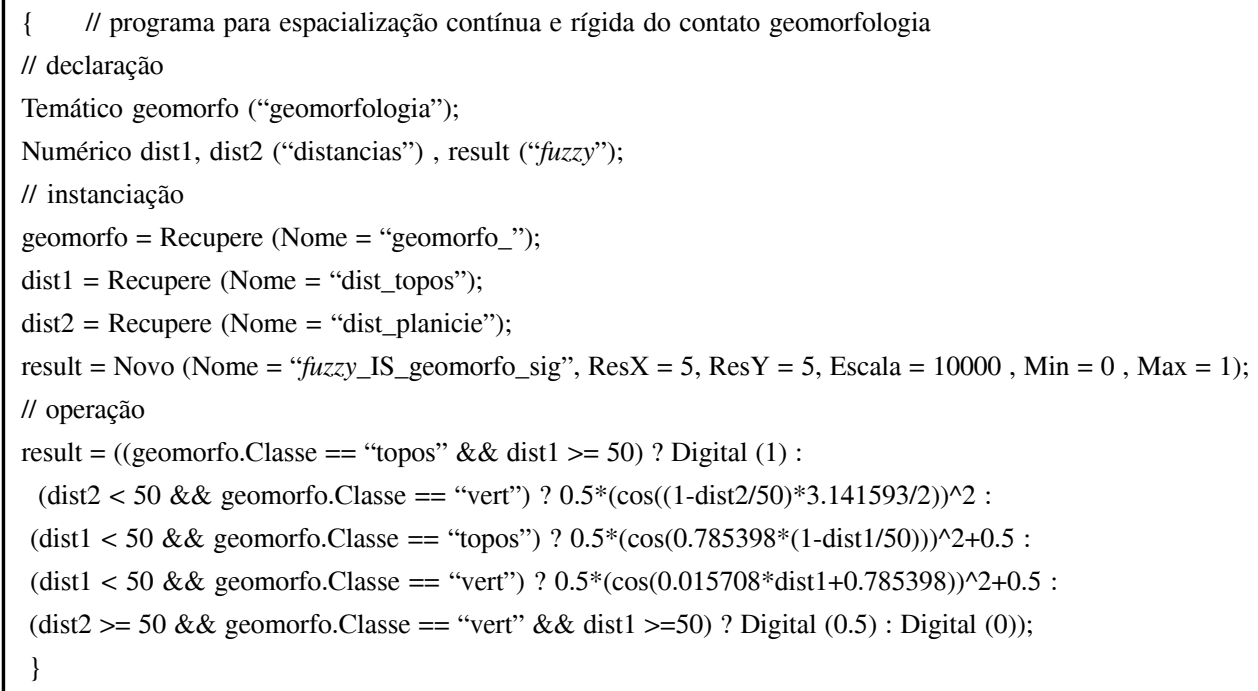

Figura 4 - Código em legal para geração de superfície da geomorfologia, através de funções sigmoidais.

Segundo a Figura 4, a primeira e as duas últimas condições das operações têm como objetivo retornar valores de membro fuzzy que expressam o grau de pertinência em relação aos compartimentos geomorfológicos, de 0 (planície aluvial), 0.5 (vertente) a 1 (topos), considerando corpos definidos por contatos rígidos. A segunda, terceira e a quarta definem uma função de pertinência fuzzy, que no caso é a sigmoidal.
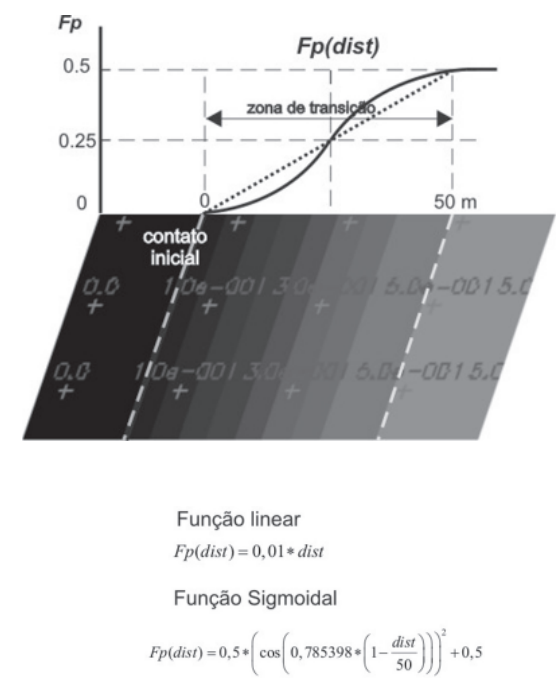

(A)
As funções lineares e sigmoidais de pertinência fuzzy graduaram os membros de modo crescente conforme a distância do contato entre as áreas de duas classes, conforme Figura 5. A zona de transição delimita a região onde os membros fuzzy expressam, no espaço, a possibilidade da localização do contato.

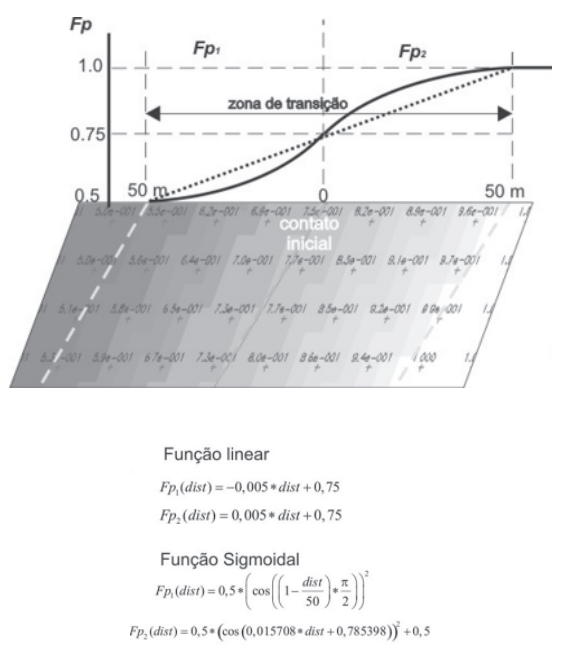

(B)

Figura 5 - (A) Função linear e sigmoidal para modelar a zona de transição de planície aluvial e a vertente. (B) Funções lineares $e$ sigmoidais aplicado para modelar a zona de transição entre a vertente e o topo. Fonte: Adaptado de Moreira (2001). 
O resultado da inferência pode ser verificado na representação da superfície dos compartimentos geomorfológicos de um pequeno trecho, na Figura 6. Na representação, a superfície que se apresenta em branco, refere-se ao topo suavemente ondulado das colinas convexas, em cinza médio o domínio das vertentes côncava-convexa, e em preto as planícies aluviais e alvéolos.

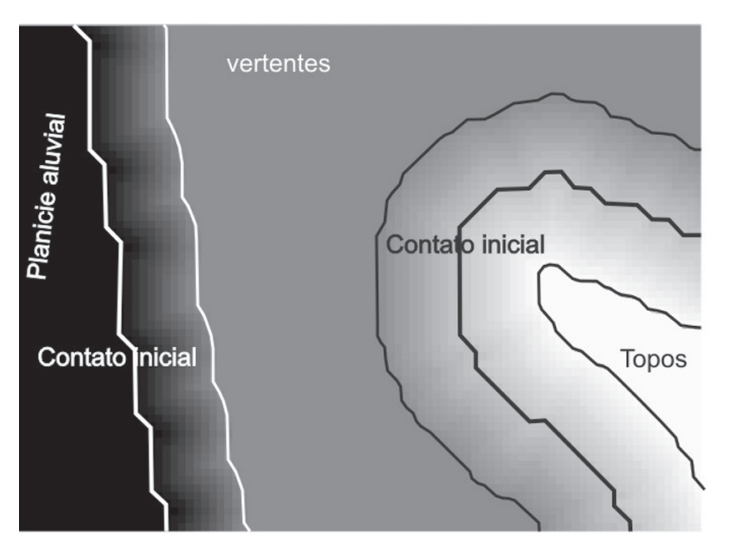

(A)

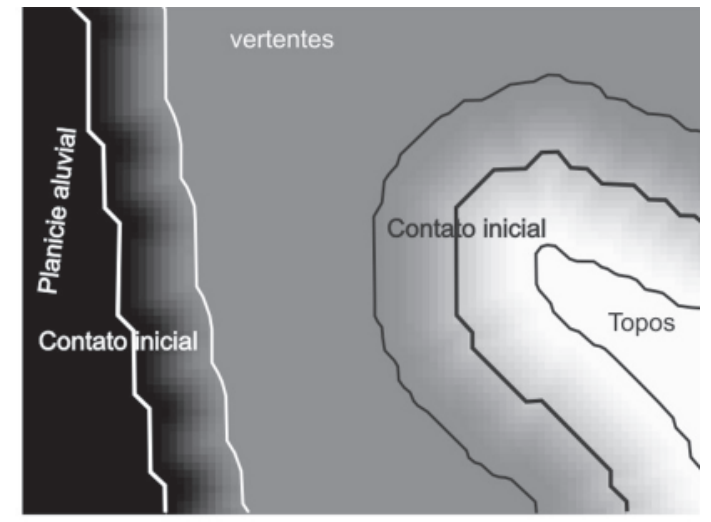

(B)

Figura 6 - Detalhe da inferência fuzzy para compartimentos entre planícies e vertentes, e entre topos e vertentes. (A) Superfície modelada a partir de funções lineares. (B) Superfície modelada a partir de funções sigmoidais.

Assim, a superfície produzida é do tipo modelo numérico do terreno (MNT), mais especificamente uma grade numérica ou matriz, a qual representa fenômenos que possuem variação contínua no espaço. O intervalo de pertinência varia de 0 (planície aluvial) a 1 (topos), sendo 0.5 valor atribuído à vertente. Nota-se que na superfície suavizada pela função sigmoidal, a transição de uma classe para outra acentua-se nas proximidades dos contatos.

\section{Considerações finais}

A discussão apresentada referente à modelagem de contato entre os limites de compartimentos de mapas geomorfológicos merece destaque à medida que essas informações vêm sendo integrada em modelos desenvolvidos em SIG. A redução da incerteza associada aos mapas temáticos é fundamental para que os especialistas possam produzir informações confiáveis, e que os modelos computacionais desenvolvidos em ambientes SIG apresentem maior aderência com o mundo real.

Destaca-se que a superfície gerada pode vir a ser utilizado como dado de entrada para modelos de inferência geográficas, como em Samizava et al. (2008), já que resultam em saídas numéricas e com um grau de ordenamento. A abordagem baseada em conjuntos nebulosos utilizada apresenta-se como uma metodologia aplicada em limites entre os compartimentos geomorfológicos, e pode ser aplicada em outros tipos de mapas temáticos, como em solos, vegetação, geologia, com suas devidas adaptações. Assim, a abordagem apresentada com- parece como importante procedimento para modelagem do meio físico, já que a inferência fuzzy apresenta uma capacidade de flexibilidade e ajuste nos dados para produzir uma representação computacional mais apropriada do mundo real.

Convém mencionar que a análise dos critérios adotados para as zonas de transição entre os compartimentos de relevo foi realizada com base na declividade média sobre a superfície de distâncias, mostrando que a definição apresentou coerência com a realidade.

A adoção de critérios objetivos possibilita uma maior redução da subjetividade na definição das zonas de transição, procedimento este que foi feito com base no conhecimento do especialista. Além disso, critérios mensuráveis possibilitam a implementação de algoritmos para modelagem de superfícies de forma automática. É evidente que o caráter de análise apresentado considere apenas valores médios e, portanto, são indicadores simples de avaliação, sendo necessário, no entanto, que outros relevos devam ser analisados para gerar modelos mais adequados.

Como a incerteza é inerente à própria natureza das feições geomorfológicas, a modelagem deve ser adaptada para diferentes escalas de representação cartográficas. O presente trabalho baseou-se numa grande escala, 1:25.000, cujos detalhes e feições geomorfológicas são diferentes de uma representação em escala de 1:100.000, por exemplo. Dessa forma, o grau de detalhamento ou tipo de feição mapeada define diferentes critérios para as zonas de transição e escolha das funções fuzzy de pertinência.

Outra proposta de aperfeiçoamento da inferência é implementar um código, segundo a abordagem por contato 
individual (individual boundary approach), proposto por Burrough e McDonell (1998). Esse tipo de abordagem leva em consideração diferentes zonas de transição, devido às características dos diferentes tipos de contatos, ou limites entre as formas mapeadas.

Nesse trabalho, consideraram-se duas funções de pertinência fuzzy. Evidentemente, a função linear é mais simples conceitualmente e de fácil implementação e considera a medida de declividade como critério de pertinência para cada classe geomorfológica. A função sigmoidal modela a zona de transição considerando que, quanto mais distante do contato, sua incerteza e imprecisão crescem não mais linearmente, mas exponencialmente.

Para finalizar, em comum acordo com Moreira (2001), a abordagem da importação semântica (IS) permitiu, de modo prático, a incorporação da natureza imprecisa dos contatos entre classes temáticas, o que representou um acréscimo de informação na modelagem. A consideração desse procedimento em análises espaciais pode minimizar erros, propagada pelos documentos elaborados por lógica booleana, durante processos de tomada de decisão.

\section{Referências bibliográficas}

ALTMAN, D. Fuzzy set theoretic approaches for handling imprecision in spatial analysis. International Journal of Geographical Information Systems, London, v.8, n.3, p. 271-290, May.-Jun. 1994.

BURROUGH, P. A.; McDONNELL, R.A. Principles of geographical information systems. Oxford, Oxford University Press, 1998.

BURROUGH, P. A. Natural objects with indeterminate boundaries. In: BURROUGH, P. A.; FRANK, A. U. (Org). Geographic objects with indeterminate boundaries. Taylor \& Francis: London, 1996. Cap1. p.3-29.

HEUVELINK, G. B. M.; BURROUGH, P. A. Error propagation in cartographyc modeling using boolean logic and continuous classification. International Journal of Geographical Information Systems, London, v.7, n.3, p. 231246, May.-Jun. 1993.
GOODCHILD, M. F.; GUOQING, S.; SHIREN, Y. Development and test of an error model for categorical data. International Journal of Geographical Information Systems, London, v.6, n.2, p. 87-104, Mar.-Apri. 1992.

LAGACHERIE, P; ANDRIEUX, P.; ROUZIGUES, R. Fuzziness and uncertainty of soil boundaries: from reality to coding in GIS. In: BURROUGH, P. A.; FRANK, A. U. (Org). Geographic objects with indeterminate boundaries. Taylor \& Francis: London, 1996. Cap8. p.275-286.

MOREIRA, F. R. S. Uso e técnicas de integração e análise espacial de dados em pesquisa mineral aplicadas ao planalto de Poços de Caldas. 2001.166p. Dissertação (Mestre em Sensoriamento Remoto) - Instituto Nacional de Pesquisas Espaciais, São José dos Campos.

NUNES, J. O. R. Uma contribuição metodológica ao estudo da dinâmica da paisagem aplicada a escolha de áreas para construção de aterro sanitário em Presidente Prudente - SP. 2002. 209p. Tese (Doutorado em Geografia) - Faculdade de Ciência e Tecnologia, Universidade Estadual Paulista, Presidente Prudente.

NUNES, J. O. R.; FREIRE, R.; PEREZ, I. U. Mapeamento geomorfológico do perímetro urbano de Presidente Prudente-SP. In: Simpósio Nacional de Geomorfologia e Regional Conference on Geomorphology, 2006, Goiânia - GO.

NUNES, J. O. R.; MARTIN, E. S.; IMAI, N.N.; KAIDA, R. H.; SAMIZAVA, T. M. A importância do conhecimento geomorfológico na análise espacial: escolha de áreas para construção de aterro sanitário no município de Presidente Prudente - SP. In: VI Simpósio Nacional de Geomorfologia e Regional Conference on Geomorphology, 2006.

SAMIZAVA, T. M.; KAIDA, R. H.; IMAI, N. N.; NUNES, J. O. R. SIG aplicado à escolha de áreas potenciais para instalação de aterros sanitários no município de Presidente Prudente - SP. Revista Brasileira de Cartografia, v. 60, p. 43-55, 2008.

SILVA, S. F.; PEJON, O. J. Utilização de inferência de lógica fuzzy na elaboração de documentos cartográficos. In: $5^{\circ}$ Simpósio Brasileiro de Cartografia Geotécnica e Geoambiental, 2004, São Carlos - SP. 